\title{
Flow cytometry evaluation of lead and cadmium effects on mouse spermatogenesis
}

\author{
Helena Oliveira $^{\text {a,b }}$, João Loureiro ${ }^{\text {a }}$, Luísa Filipe ${ }^{\mathrm{a}}$, Conceição Santos ${ }^{\mathrm{a}, *}$, \\ João Ramalho-Santos ${ }^{\mathrm{c}}$, Mário Sousa ${ }^{\mathrm{d}}$, Maria de Lourdes Pereira ${ }^{\mathrm{a}, \mathrm{b}}$ \\ ${ }^{a}$ Department of Biology, University of Aveiro, Campus Universitario de Santiago, 3810-193 Aveiro, Portugal \\ ${ }^{\mathrm{b}}$ CICECO, University of Aveiro, Campus Universitário de Santiago, 3810-193 Aveiro, Portugal \\ ${ }^{\mathrm{c}}$ Center for Neuroscience and Cell Biology, Department of Zoology, University of Coimbra, 3004-517 Coimbra, Portugal \\ ${ }^{\mathrm{d}}$ Lab Cell Biology, Institute of Biomedical Sciences Abel Salazar (ICBAS), University of Porto, Lg. Prof. Abel Salazar 2, 4099-003 Porto, Portugal
}

Received 22 November 2005; received in revised form 2 February 2006; accepted 3 March 2006

Available online 2 May 2006

\begin{abstract}
Flow cytometry (FCM) is a powerful tool to evaluate cell DNA content and ploidy levels. We have assessed the accuracy of two protocols of nuclei isolation from paraffinized samples (P1 and P2) by comparing FCM results with those obtained using fresh material (F1-F3). After isolation, nuclei were stained with propidium iodide and quantitatively analysed by FCM for changes in germ cell ratios. Results obtained with Protocol P2 were similar to those obtained using the protocol that gave best results for fresh tissues (F2). Protocol P2 was then applied to paraffin embedded testicular samples from ICR-CD1 mice exposed to 1,2 and $3 \mathrm{mg} \mathrm{CdCl} / \mathrm{kg}$ bw by single subcutaneous injection, and to 74 and $100 \mathrm{mg} \mathrm{PbCl} 2 / \mathrm{kg}$ bw administered in four repeated doses. The highest doses of $\mathrm{CdCl}_{2}$ decreased the number of haploid (1C) cells and increased the number of diploid (2C), S phase and tetraploid (4C) cells. Treatment with $\mathrm{PbCl}_{2}$ did not induce significant changes in testicular cells subpopulations. These results support the usefulness of FCM in evaluating the effect of toxic substances on mouse spermatogenesis, using both fresh and paraffinized material.
\end{abstract}

(C) 2006 Elsevier Inc. All rights reserved.

Keywords: Cadmium chloride; Flow cytometry; Lead chloride; Spermatogenesis; Testicular toxicity

\section{Introduction}

Flow cytometry (FCM) is a fast and sensitive tool that can provide quantitative analyses of different cell types and an insight into the cell cycle status of those cells. FCM also allows the measurement of DNA content of cell subpopulations in a mixed cell population, using fluorescence intensity distribution histograms, enabling the identification of cells with different ploidy levels within a given tissue [1,2].

FCM has been applied to the study of the toxic effect of substances on spermatogenesis of several species, namely mouse [1,3,4], rat [5,6] and golden hamster [7]. Alterations in testicular germ cell percentages are common responses to chemicals such as vinblastine [3], vindesine sulphate [8],

\footnotetext{
* Corresponding author. Tel.: +351 234370 780; fax: +351 234426408 .

E-mail address: csantos@bio.ua.pt (C. Santos).
}

diepoxybutane [1] or methoxyacetic acid [9]. In all cases FCM analyses were performed in nuclei isolated from fresh material. The specific methodologies are quite variable, and include $0.1 \%$ pepsin digestion [1], tripsin and DNAse digestion [5] and testis dissection in TNE $(0.01 \mathrm{M}$ Tris buffer, $0.15 \mathrm{M} \mathrm{NaCl}, 0.01 \mathrm{M}$ ethylenediaminetetraacetic acid, $\mathrm{pH}$ 7.4) buffer [7]. Other authors prepare nuclei for FCM analysis using citric acid with detergent solutions [10]. Nevertheless, the general requirement for fresh material may condition a broader utilization of FCM in these kinds of studies.

In most laboratories interested in toxicology, histological evaluation of tissues and organs is performed routinely, and usually includes paraffin embedding. In the present work, the possibility of using FCM to analyse mouse testicular cells from embedded samples was assessed. This technique has been developed by Hedley et al. [11] to study DNA content in tumoral samples, and since that time it has been routinely used at the clinical oncology level. Therefore, the development of 
a FCM protocol for testicular cell analysis, especially in cases where spermatogenesis is affected, may be a valuable tool in the reproductive toxicology field.

Cadmium is a well-known reproductive toxicant that causes disruption of the blood-testis barrier [12]. Several works describing the histological and ultrastructural effects of cadmium in the testis have been published (e.g. $[13,14])$. However, the quantification of cadmium-induced alterations in spermatogenesis, in terms of the relative percentages of each testicular cell type, has never been performed. Also, the toxicological effects of lead on male reproductive system have long been studied. The main effects referred in the literature are a decrease in sperm cell number and motility $[15,16]$, and an increase in sperm morphological abnormalities [15]. Although histopathological effects of lead compounds on the testis have been previously described (e.g. $[16,17])$, those studies have not used more refined techniques such as FCM.

The aim of the present work is thus to demonstrate that, in alternative to fresh material, paraffin embedded samples of testicular material might be used to accurately determine the ploidy level of germ cells using FCM. The validation of paraffinized samples for FCM nuclei analyses was done by comparing the results with data obtained using fresh material. The validated protocol was then used to assess the toxic effect of cadmium and lead chloride on mouse spermatogenesis, at the level of each specific cell-stage.

\section{Materials and methods}

\subsection{Animal housing}

Seven weeks old male ICR-CD1 mice were provided by Harlan Interfauna Ibérica SA, Barcelona, Spain. The animals were housed in a constant temperature $\left(22 \pm 2{ }^{\circ} \mathrm{C}\right)$ and relative humidity $(40-60 \%)$ vivarium on a 12 -h light/12-h dark cycle. Water and food were provided ad libitum. Mice were allowed to acclimate for one week before experimental use.

Animal experiments were conducted in accordance with institutional guidelines for ethics in animal experimentation (Rule number 86/609/CEE-24/ 11/92).

\subsection{Flow cytometric analysis of fresh and paraffinized samples}

Different protocols for the isolation of mouse testicular cells were used from both fresh and paraffin embedded tissues. For each protocol at least four testes from different mice were used.

\subsubsection{Fresh samples}

Three different protocols for nuclei isolation from fresh samples were tested: Protocol F1: Samples were prepared according to a protocol developed for the golden hamster [7]. Briefly, testes were dissected in TNE buffer ( $0.01 \mathrm{M}$ Tris buffer, $0.15 \mathrm{M} \mathrm{NaCl}, 0.01 \mathrm{M}$ ethylenediaminetetraacetic acid, $\mathrm{pH}$ 7.4), filtered with a nylon mesh of $55 \mu \mathrm{m}$ and the cell suspensions that were obtained were supplemented with glycerol $10 \%(\mathrm{v} / \mathrm{v})$ and stored at $-20{ }^{\circ} \mathrm{C}$ until analysis. Thereafter, cell suspensions were thawed and centrifuged at $500 \times g$ for $5 \mathrm{~min}$ and resuspended in TNE buffer.

Protocol F2: This protocol was based on the protocol described by Spanò et al. [1] for mouse testicular cells. Briefly, testes were dissected in $0.1 \%$ pepsin- $\mathrm{HCl}$ at $\mathrm{pH} 1.8$ for $10 \mathrm{~min}$. After filtration, the cell suspension was fixed in $96 \%$ ethanol and kept at $-20{ }^{\circ} \mathrm{C}$. After that, cell suspensions were incubated with pepsin- $\mathrm{HCl} 0.5 \%$ for $10 \mathrm{~min}$, centrifuged at $500 \times \mathrm{g}$ for $10 \mathrm{~min}$ and resuspended in phosphate buffered saline (PBS).
Protocol F3: In this case, testes were dissected in $0.1 \mathrm{M}$ citric acid and $0.5 \%$ (v/v) Tween 20 and incubated for $10 \mathrm{~min}$ at RT. After filtration in a $55 \mu \mathrm{m}$ nylon mesh, the suspension was centrifuged at $300 \times g$ for $10 \mathrm{~min}$, the supernatant was then discarded and the pellet was resuspended in a small volume of PBS. The suspension was fixed in $70 \%^{\circ}$ ethanol and was kept for a few days. After that, the cell suspension was centrifuged and cells were resuspended in detergent solution, incubated for $10 \mathrm{~min}$ at RT and finally 5 volumes of a $0.4 \mathrm{M}$ $\mathrm{Na}_{2} \mathrm{HPO}_{4}$ solution were added.

\subsubsection{Paraffin embedded material}

Two protocols for isolation of nuclei from paraffin embedded samples were assayed. In both protocols two or more sections ( $40 \mu \mathrm{m}$ thick) of five blocks corresponding to five different mice were used. Sections were deparaffinized in xylol and rehydrated.

In Protocol P1, samples were incubated in a water bath at $80^{\circ} \mathrm{C}$ with citric acid $2 \mathrm{mg} \mathrm{mL}^{-1}$ at $\mathrm{pH} 6.0$ for $2 \mathrm{~h}$, digested with pepsin, $\mathrm{pH} 1.5$, at $37^{\circ} \mathrm{C}$ and washed in PBS [11,18].

Protocol P2 was similar to Protocol P1 except for the incubation with citric acid, which was not performed [19].

\subsubsection{Flow cytometry analysis}

In all protocols (F1-F3, P1 and P2), samples were treated with $50 \mu \mathrm{g} \mathrm{mL}^{-1}$ of RNAse (Sigma, St. Louis, MO, USA) in order to eliminate RNA, and stained with $50 \mu \mathrm{g} \mathrm{mL}^{-1}$ of propidium iodide (PI). Samples were analysed within a 15-min period. The relative fluorescence intensity of PI-stained nuclei was measured with a Coulter EPICS XL (Coulter Electronics, Hialeah, FL, USA) flow cytometer. The instrument was equipped with an air-cooled argon-ion laser tuned at $15 \mathrm{~mW}$ and operating at $488 \mathrm{~nm}$. Integral fluorescence together with fluorescence pulse height and width emitted from nuclei was collected through a 645 dichroic long-pass filter and a 620 band-pass filter and converted on 1024 ADC channels. Prior to analysis, the instrument was checked for linearity with fluorescent check beads (Coulter Electronics) and the amplification was adjusted so that the peak corresponding to the haploid peak was positioned at channel 200. This setting was kept constant. The results were obtained in the form of three graphics: linear fluorescence light intensity (FL), forward angle light scatter (FS) versus side angle light scatter (SS) and FL pulse integral versus FL pulse height. This last cytogram was used to eliminate partial nuclei and other debris, nuclei with associated cytoplasm and doublets (these events have a higher pulse area but the same pulse height as single nuclei).

\subsection{Heavy metal treatment assays}

For toxicological studies, ICR-CD1 mice were housed in the conditions described in Section 2.1. For cadmium toxicological assays three groups of five mice each were subcutaneously injected with 1,2 or $3 \mathrm{mg} \mathrm{CdCl}_{2} / \mathrm{kg}$ bw. For lead toxicological assays two groups of five mice each were subcutaneously injected with 74 and $100 \mathrm{mg} \mathrm{PbCl} / 2 / \mathrm{kg}$ bw for four consecutive days. In both experiments control groups of five mice each were injected with the saline vehicle $(0.9 \%$ $\mathrm{NaCl})$ for equivalent periods.

Twenty-four hours after the last injection, animals were sacrificed and both testes were removed, the right testis was fixed in neutral $10 \%$ buffered formalin and the left testis was fixed in Bouin's solution. Both samples were then dehydrated and embedded in paraffin wax. For the histopathology analysis sections were performed in a microtome and stained with haematoxylin and eosin. For FCM analysis samples were treated as described above for Protocol $\mathrm{P} 2$.

\subsection{Statistical analysis}

Statistical analyses were performed using a one-way analysis of variance (ANOVA) (SigmaStat for Windows Version 3.1, SPSS Inc., USA) to compare the values of germ cell percentages. A multiple comparison Tukey test was applied to assay the differences between control and metal treated groups. The correlations between the results obtained with the different treatments were performed by the Pearson Correlation test [20]. In all cases the level of statistic significance was set at $p \leq 0.05$. 


\section{Results}

\subsection{Flow cytometric analysis of fresh and paraffinized samples}

Forward angle light scatter is proportional to cell-surface area or size and side angle light scatter is proportional to cell granularity or internal complexity. The different methods of nuclei isolation gave different results in terms of nuclei light scatter properties. Nuclei isolated from fresh samples (Protocols F2 and F3) were homogeneously distributed in one single population (Fig. 1A and D). Contrarily, the nuclei from embedded origin showed discrete populations in terms of relative size and complexity (Fig. $1 \mathrm{G}$ and J). The best separation of nuclei in terms of light scatter was observed in nuclei isolated using Protocol P2 (Fig. 1J).

Linear fluorescence light intensity represents the linear fluorescence of the DNA stained with PI (Fig. 1B, E, H and L). Protocol F1 produced unsatisfactory definition of peaks and for this reason the results are not presented. DNA histograms from the other two fresh and both embedded samples revealed four main peaks corresponding to different ploidy levels. The sub-haploid peak (HC) consists of elongated spermatids and the haploid peak (1C) refers to round spermatids. The discrimination of the haploid nuclei in two peaks is due to different staining of elongated and round spermatids, since the former present a highly condensed chromatin and PI intercalation with DNA is lower. Chromatin condensation occurs as a result of the sperm maturation process where exchange of histones with protamines reduces PI intercalation [21]. Somatic cells, spermatogonia and secondary spermatocytes are recorded in the diploid peak (2C). Cells in the $\mathrm{G}_{2} / \mathrm{M}$ phase of the cell cycle and primary spermatocytes are included in the tetraploid peak (4C). The region between the diploid and the tetraploid peaks corresponds to cells that are actively synthesising DNA (S phase).

The mean CV obtained for all protocols are shown in Fig. 1B, $\mathrm{E}, \mathrm{H}$ and $\mathrm{L}$. The higher values were found in the HC subpopulation. This higher $\mathrm{CV}$ value can be explained by the chromatin status of the HC nuclei (elongated spermatids), that present different degrees of chromatin condensation, due to different degrees of PI intercalation between the bases.

The cytograms with pulse integral versus pulse height were computed to define a gating that excludes doublets. Nuclei from fresh samples (Fig. 1C and F) showed more doublets than paraf- fin samples (Fig. 1I and M), with the lower number of doublets being observed in Protocol P2.

Protocols F2 and F3 gave different results $(p<0.001)$ with respect to the subpopulation ratios. Both Protocols F2 and F3 presented similar discrete peaks and CV's. However, some differences were found in the percentage of each subpopulation obtained by each protocol: with the Protocol F2 (Figs. 1B and 2), the $\mathrm{HC}$ subpopulation represented $34 \%$ of the nuclei population, whereas it represented only $17 \%$ of the nuclei isolated with the Protocol F3 (Figs. 1E and 2). In paraffin embedded tissues, the ploidy percentages were similar to the values obtained using Protocol F2 (Fig. 2). The results obtained with Protocol F2 were positively correlated with those obtained by both Protocol P1 and P2 (Pearson correlation, $r>0.96, p=0.007$ for Protocol P1 and $p=0.009$ for Protocol P2). Paraffin protocols were also positively correlated with each other (Pearson correlation, $r=0.992$; $p=0.0008$ ). For toxicological assays we therefore chose Protocol P2 for FCM analyses.

\subsection{Heavy metal treatment assays}

The highest doses of cadmium chloride ( 2 and $3 \mathrm{mg} / \mathrm{kg} \mathrm{bw}$ ) induced a significant increase in absolute and relative testis weight after $24 \mathrm{~h}$, but both body weight and absolute and relative weights of the epididymis were not affected by cadmium chloride treatment (Table 1). In the lead chloride assay neither testis nor epididymis weights were significantly affected (Table 2).

Cadmium chloride at the concentration of $1 \mathrm{mg} / \mathrm{kg}$ bw did not induce any histological alteration to the seminiferous epithelium (Fig. 3B). The higher concentrations of cadmium chloride ( 2 and $3 \mathrm{mg} / \mathrm{kg}$ bw) provoked severe alterations in the seminiferous tubules, namely haemorrhage, interstitial edema and disruption of the germinal epithelium with desquamation of cells into the lumen (Fig. 3C and D), particularly at the highest concentrations of compound. Lead chloride did not induce any typical changes on testis histology, in terms of percentage of tubules with germ cell degeneration or depletion, and tubular diameter when compared with the respective controls $(p \leq 0.05)$ (data not shown).

FCM analyses showed that the relative percentage of subhaploid nuclei (elongated spermatids) was significantly reduced $(p \leq 0.05)$ following administration of 2 and $3 \mathrm{mg} \mathrm{CdCl} / 2 \mathrm{~kg}$ bw (Fig. 4). Administration of $3 \mathrm{mg} \mathrm{CdCl} / 2 / \mathrm{kg}$ bw decreased the percentage of haploid cells (round spermatids) $(p \leq 0.005)$.

Table 1

Effect of cadmium chloride on testis/body weight and epididymis/body weight ratios

\begin{tabular}{|c|c|c|c|c|}
\hline & Control $(n=9)$ & $1 \mathrm{mg} / \mathrm{kg}$ bw $(n=10)$ & $2 \mathrm{mg} / \mathrm{kg}$ bw $(n=10)$ & $3 \mathrm{mg} / \mathrm{kg}$ bw $(n=10)$ \\
\hline Body weight (g) & $33.23 \pm 2.536$ & $33.50 \pm 2.257$ & $33.31 \pm 2.105$ & $34.40 \pm 1.808$ \\
\hline Testis weight $(\mathrm{g})$ & $0.114 \pm 0.017$ & $0.106 \pm 0.011$ & $0.144 \pm 0.033^{*}$ & $0.156 \pm 0.026^{*}$ \\
\hline Epididymis weight (g) & $0.046 \pm 0.007$ & $0.041 \pm 0.006$ & $0.045 \pm 0.006$ & $0.046 \pm 0.007$ \\
\hline Epididymis/body weight ratio (\%) & $0.141 \pm 0.018$ & $0.122 \pm 0.017$ & $0.135 \pm 0.020$ & $0.132 \pm 0.017$ \\
\hline
\end{tabular}

Values represent mean \pm S.D.

The symbol * means significant difference between the control and 1,2 and $3 \mathrm{mg} \mathrm{CdCl}_{2}$ treated samples at $p \leq 0.05$. 

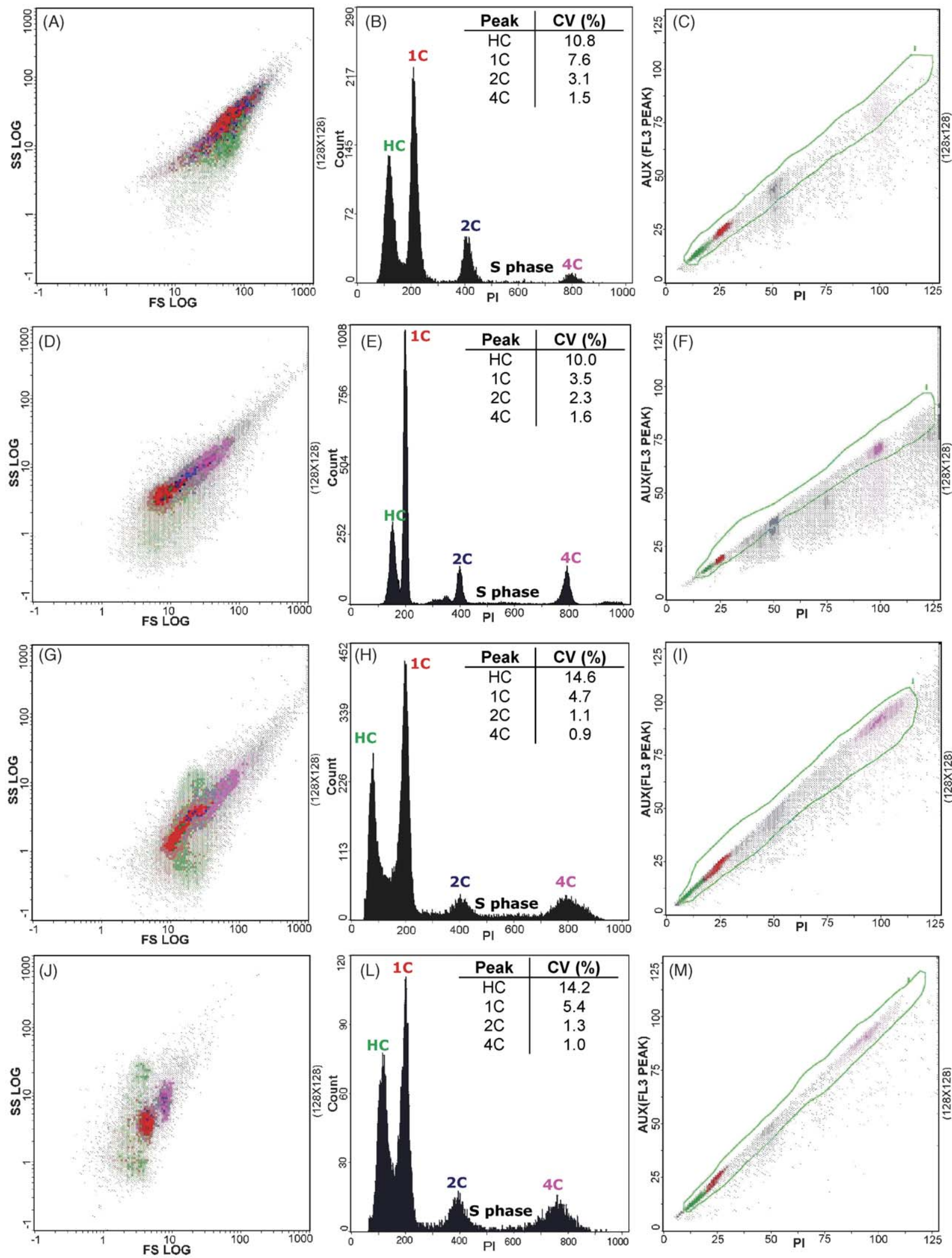

Fig. 1. Flow cytometry graphics of nuclei isolated from fresh tissue by the Protocol F2 (A-C) and Protocol F3 (D-F) and paraffin embedded tissue by Protocol P1 (G-I) and Protocol P2 (J, L and M). The left column cytograms show the forward angle light scatter (FS) vs. side angle light scatter (SS), the middle column histograms show the relative fluorescence light intensity (FL) from propidium iodide and the right column cytograms show the relative FL pulse integral vs. relative FL pulse height. 


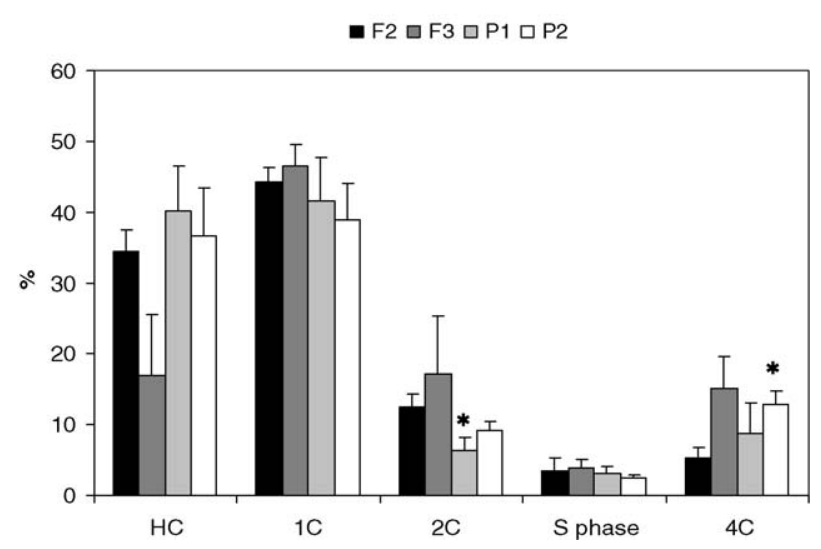

Fig. 2. Ploidy percentage variation of germ cells isolated by the Protocol F2, Protocol F3 (fresh tissue), Protocol P1 and Protocol P2 (paraffin embedded tissue). Percentages were estimated as number of nuclei in each ploidy level/total number of nuclei $\times 100$ and represent mean \pm S.D. for at least four testicular samples. The symbol ' $*$ ' indicates significant difference between the fresh and paraffin methods at $p \leq 0.05$.

Concomitantly, the percentage of diploid cells increased following treatment with 2 and $3 \mathrm{mg} \mathrm{CdCl} / \mathrm{kg}$ bw. The same was observed for cells in $\mathrm{S}$ phase by treatment, in this case for all cadmium doses. In what concerns tetraploid cells a significant

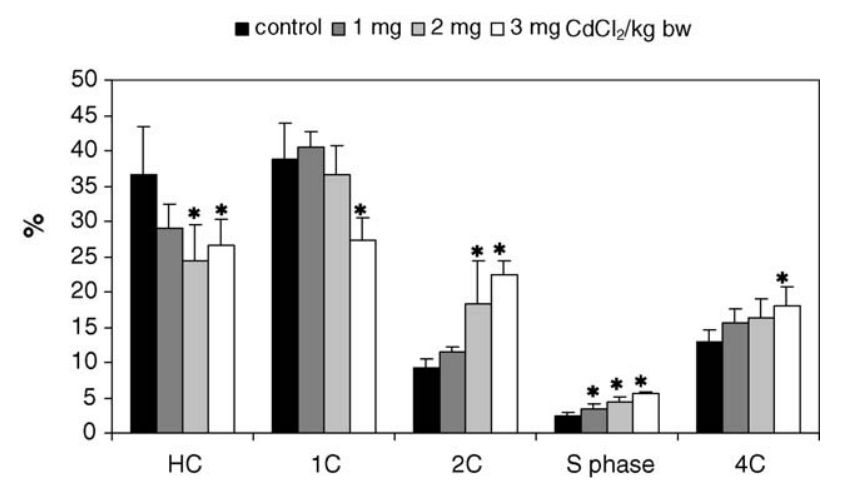

Fig. 4. Percentage of germ cells isolated from testis of control and exposed to 1,2 and $3 \mathrm{mg}$ of $\mathrm{CdCl}_{2} / \mathrm{kg}$ bw mice. Percentages were estimated as number of nuclei in each ploidy level/total number of nuclei $\times 100$ and represent mean \pm S.D. from five testes (one per mice) per group. The symbol ' $*$ ' indicates significant difference between the control and 1,2 and $3 \mathrm{mg} \mathrm{CdCl} 2$ treated samples at $p \leq 0.05$.

increase $(p \leq 0.05)$ was only found after administration of $3 \mathrm{mg} \mathrm{CdCl} / \mathrm{kg}$ bw.

The lead chloride treatment induced some variations in the percentage of germ cells, although the only one that was statistically significant $(p \leq 0.05)$ was an increase in the percentage of cells in $\mathrm{S}$ phase with $100 \mathrm{mg} \mathrm{PbCl} / 2 / \mathrm{kg}$ bw (Fig. 5).

Table 2

Effect of lead chloride on testis/body weight and epididymis/body weight ratios

\begin{tabular}{lrrr}
\hline & Control $(n=10)$ & $74 \mathrm{mg} / \mathrm{kg}$ bw $(n=10)$ & $100 \mathrm{mg} / \mathrm{kg}$ bw $(n=10)$ \\
\hline Body weight $(\mathrm{g})$ & $36.294 \pm 2.988$ & $36.444 \pm 2.330$ & $36.758 \pm 3.518$ \\
Testis weight $(\mathrm{g})$ & $0.123 \pm 0.018$ & $0.124 \pm 0.016$ & $0.128 \pm 0.025$ \\
Epididymis weight (g) & $0.047 \pm 0.005$ & $0.049 \pm 0.005$ & $0.048 \pm 0.006$ \\
Testis/body weight ratio (\%) & $0.340 \pm 0.040$ & $0.341 \pm 0.048$ & $0.353 \pm 0.088$ \\
Epididymis/body weight ratio (\%) & $0.130 \pm 0.009$ & $0.135 \pm 0.016$ & $0.130 \pm 0.019$ \\
\hline
\end{tabular}

Values represent mean \pm S.D. No statistical differences were found at $p \leq 0.05$.
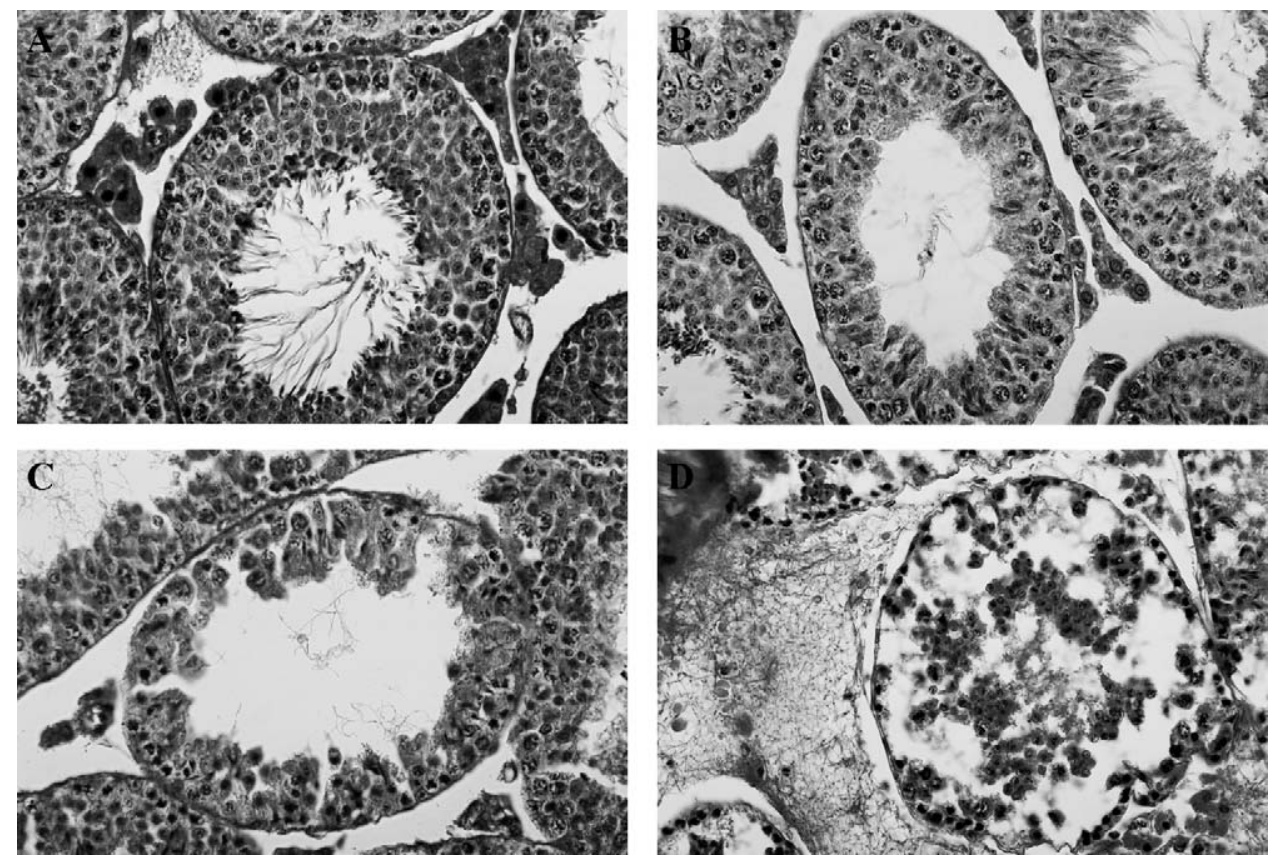

Fig. 3. Histological effects of 1,2 and $3 \mathrm{mg}$ of $\mathrm{CdCl}_{2}$ to mice testis. (A) Control, (B) $1 \mathrm{mg} \mathrm{CdCl} / \mathrm{kg}$ bw, (C) $2 \mathrm{mg} \mathrm{CdCl} / \mathrm{kg}$ bw and (D) $3 \mathrm{mg} \mathrm{CdCl} / 2 \mathrm{~kg}$ bw. 


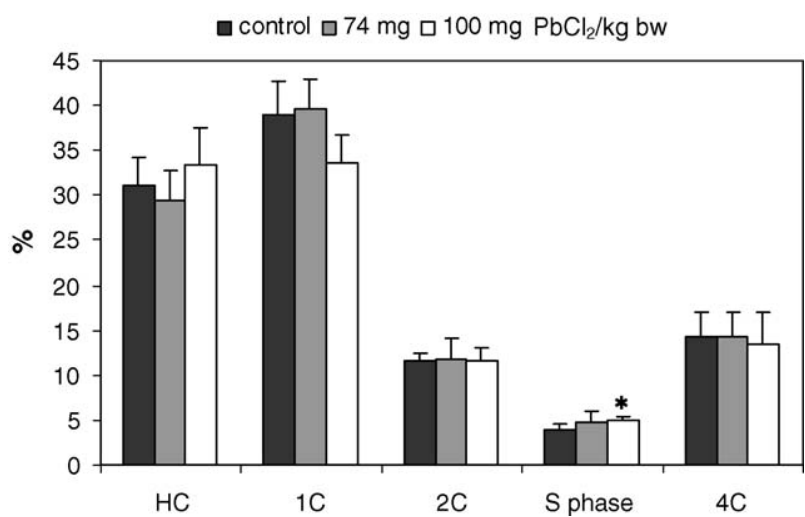

Fig. 5. Percentage of germ cells isolated from testis of control and exposed to 74 and $100 \mathrm{mg}$ of $\mathrm{PbCl}_{2} / \mathrm{kg}$ bw mice. Percentages were estimated as number of nuclei in each ploidy level/total number of nuclei $\times 100$ and represent mean \pm S.D. from five testes (one per mice) per group. The symbol ' $*$ ' indicates significant difference between the control and 74 and $100 \mathrm{mg}$ of $\mathrm{PbCl}_{2}$ treated samples at $p \leq 0.05$.

\section{Discussion}

The development of protocols for isolation of nuclei from non-fresh samples may potentiate the use of FCM in reproductive toxicology studies. As Bouin's fixation is routinely used for the study of spermatogenesis [22] its efficacy was evaluated in nuclei fixation for FCM studies. However, this fixative did not produce satisfactory results in terms of DNA content analysis, just as described previously by Hedley [18]. Therefore, Bouin's solution was used for histology analysis and buffered formalin for DNA studies by FCM.

The different methods used to isolate mice testicular nuclei from fresh samples gave clearly different results. Although it has been used successfully in the golden hamster [7], Protocol F1 did not provide a clear definition of peaks, possibly due to species-specific differences in the isolation of nuclei. Protocol F3 has been used for DNA analysis of animal cells [10] and provided a good peak definition (the CV values obtained were among the best), as well as low level of debris. However, this method induced the formation of a great number of doublets and the elongated spermatid population was underestimated, probably due to the high ionic strength of the buffers used. Finally, Protocol F2 provided a good peak definition, and the percentages of cells in the different ploidy levels are consistent with the results previously obtained by other authors [1,3]. On the other hand, although Protocol F3 gave discrete peaks, the CV's obtained showed no great improvement when compared with Protocol F2. As the former is more time consuming and aggressive than the latter, we propose that Protocol F2 is more advisable for this type of studies.

The two protocols of nuclei isolation from paraffin samples gave similar results. However, Protocol P2 was more reproducible in terms of the number of nuclei run per minute (data not shown), probably due to the fewer steps involved. Protocol P2 was therefore selected to evaluate the effect of cadmium chloride and lead chloride on mouse testis.
Cadmium chloride induced an increase in absolute and relative testes weight $24 \mathrm{~h}$ after administration. This effect was also observed by Shen and Sangiah [23], and it was hypothesized that it could be due to damage of the capillary endothelium and subsequent increase in permeability that lead to testicular edema. This effect on testicular weight was reversed as the time after exposure increased (data not shown). Histological evaluation showed that cadmium chloride seriously injured the testis. These short term effects of cadmium were also observed by FCM, in terms of significant alterations in germ cell percentages. These changes may be due to the effects of $\mathrm{CdCl}_{2}$ on both the blood-testis barrier and vascular endothelium. Cadmium disrupts tight junctions between Sertoli cells and alters Sertoli-germ cell adhesion [12] with consequent exfoliation of spermatids within the seminiferous tubules. This effect is supported by the presence of immature cells in the epididymis lumen (data not shown) and could therefore explain the decrease in the percentage of spermatids observed by FCM. Alternatively, non-specific germ cell degeneration and death can occur due to anoxia caused by changes in interstitial vasculature. No significant changes in mice testis/body weight or epididymis/body weight ratios were observed following treatment with lead chloride, similarly to what was described by Wadi and Ahmad [15]. Lead chloride did not induce striking changes in testis histology. This result was reflected in the absence of alterations in the percentages of testicular germ cells detected by FCM, with the exception of an increase in the percentage of cells in S phase. We hypothesize that this increase may be related with the mitogenic activity of lead previously described in lymphocytes [24] and liver cells [25]. Pinon-Lataillade et al. [26] also did not find prominent alterations in the reproductive system of male rats after exposure to lead oxide or lead acetate. These results suggest that the blood-testis barrier protects the seminiferous epithelium from the toxic effects of lead. The absence of damage to the blood-testis barrier by lead has also been pointed out by other authors $[15,27]$.

In this work we demonstrated that buffered formalin fixed and paraffin embedded material allows good DNA preservation and enables cell extraction and quantification by FCM analysis in toxicological assays using mouse testicular tissue. The great advantage of this technique is that it allows long-term storage of samples and the possibility of making several replicas, thus increasing reliability. Paraffin embedded DNA analysis of testicular cells by FCM should be considered as an useful approach for the screening of substances in terms of testicular toxicity, as well as an important complement to histopathology.

\section{Acknowledgements}

Authors thank the Research Institute of the University of Aveiro (Project CTS/22) and CICECO for financial support. João Ramalho-Santos was supported by a grant from FCT, Portugal (POCTI/ESP/38049/2001). Helena Oliveira was supported by a grant from Research Institute of the University of Aveiro (Project CTS/22). João Loureiro was supported by a grant from FCT, Portugal (FCT/SFRH/BD/9003/2002). 


\section{References}

[1] Spanò M, Bartoleschi C, Cordelli E, Leter G, Segre L. Flow cytometric and histological assessment of 1,2:3,4-diepoxybutane toxicity on mouse spermatogenesis. J Toxicol Environ Health 1996;47:423-41.

[2] Spanò M, Evenson DP. Flow cytometric analysis for reproductive biology. Biol Cell 1993;78:53-62.

[3] Jagetia GC, Krishnamurthy H, Jyothy P. Evaluation of cytotoxic effects of different doses of vinblastine on mouse spermatogenesis by flow cytometry. Toxicology 1996;112:227-36.

[4] Oskam IC, Ropstad E, Smith AJ, Skaare JU, Tverdal A, Berg KA, et al. Effects of PCB99 and PCB153 exposure on spermatogenesis in young adult C57BL6 mice. Reprod Toxicol 2004;19(2):169-80.

[5] Sutter L, Koch E, Bechter R, Bobadilla M. Three-parameter flow cytometric analysis of rat spermatogenesis. Cytometry 1997;27:161-8.

[6] Blake CA, Boockfor FR, Nair-Menon JU, Millette CF, Raychoudhury SS, McCoy GL. Effects of 4-tert-octylphenol given in drinking water for 4 months on the male reproductive system of Fischer 344 rats. Reprod Toxicol 2004;18:43-51.

[7] Golan R, Vigodner M, Oschry Y, Schocat L, Lewin LM. Chromatin condensation during spermiogenesis in the golden hamster (Mesocricetus aureus): a flow cytometric study. Mol Reprod Dev 2000;56:105-12.

[8] Jagetia GC, Jyothi P, Krishnamurthy H. Flow cytometric evaluation of the effect of various doses of vindesine sulphate on mouse spermatogenesis. Reprod Toxicol 1997;11:867-74.

[9] Suter L, Meier G, Bechter R, Bobadilla M. Flow cytometry as a sensitive tool to access testicular damage in rat. Arch Toxicol 1998;72:791-7.

[10] Otto FJ. Preparation of cells for light-resolution DNA analysis. In: Radbuch A, editor. Flow cytometry and cell sorting. Berlin: Springer-Verlag; 1992.

[11] Hedley DW, Friedlander ML, Taylor IW, Rugg CA, Musgrove EA. Method for analysis of cellular DNA content of paraffin embedded pathological material using flow cytometry. J Histochem Cytochem 1983;31:1333-5.

[12] Hew KW, Heath GL, Jiwa AH, Welsh MJ. Cadmium in vivo causes disruption of tight junction-associated microfilaments in rat Sertoli cells. Biol Reprod 1993;49:840-9.

[13] Hew KW, Ericson WA, Welsh MJ. A single low cadmium dose causes failure of spermiation in the rat. Toxicol Appl Pharmacol 1993; 121:15-21.
[14] Aoki A, Hoffer AP. Re-examination of the lesions in rat testis caused by cadmium. Biol Reprod 1978;18:579-91.

[15] Wadi SA, Ahmad G. Effects of lead on male reproductive system in mice. J Toxicol Environ Health 1999;56:513-21.

[16] Graça A, Ramalho-Santos J, Pereira ML. Effect of lead chloride on spermatogenesis and sperm parameters in mice. Asian J Androl 2004;6:237-41.

[17] Marchlewicz M, Protasowicki M, Rozewicka L, Piasecka M, Laszczynska M. Effect of long-term exposure to lead on testis and epididymis in rats. Folia Histochem Cytobiol 1993;31:55-62.

[18] Hedley DW. Flow cytometry using paraffin-embedded tissue: five years on. Cytometry 1989;10:229-41.

[19] Mora LB, Moscinski LC, Diaz JI, Blair P, Cantor AB, Pow-Sang JM. Stage B prostate cancer: correlation of DNA ploidy analysis with histological and clinical parameters. Cancer Control 1999;6:587-91.

[20] Zar JH. Biostatistical analysis. New Jersey: Prentice-Hall International Inc.; 1996.

[21] Evenson D, Darzynkiewicz Z, Jost L, Janca F, Ballanchey B. Changes in accessibility of DNA to various fluorochromes during spermatogenesis. Cytometry 1986;7:45-53.

[22] Szczech GM, Russel LD. Commentary on the application of refined morphologic evaluation of the testis to the practice of toxicologic pathology. Toxicol Pathol 1997;25:230-7.

[23] Shen Y, Sangiah S. Na+, K(+)-ATPase, glutathione, and hydroxyl free radicals in cadmium chloride-induced testicular toxicity in mice. Arch Environ Contam Toxicol 1995;29:174-9.

[24] Razani-Boroujerdi S, Edwards B, Sopori ML. Lead stimulates lymphocyte proliferation trough enhanced T cell-B cell interaction. J Pharmacol Exp Ther 1999;288:714-9.

[25] Bell CE, Baldwin LA, Kostecki PT, Calabrese EJ. Comparative responses of rainbow trout and rat to the liver mitogen lead. Ecotoxicol Environ Saf 1993;26:280-4.

[26] Pinon-Lataillade G, Thoreux-Manlay A, Coffigny H, Monchaux G, Masse $\mathrm{R}$, Soufir JC. Effect of ingestion and inhalation of lead on the reproductive system and fertility of adult male rats and their progeny. Hum Exp Toxicol 1993;12:165-72.

[27] Murthy RC, Gupta SK, Saxena DK. Nuclear alterations during acrosomal cap formation in spermatids of lead-treated rats. Reprod Toxicol 1995;9:483-9. 